\title{
Anti-Alpha-Enolase Antibodies in Pituitary Disease
}

\author{
SUSUMU TANAKA, Ke-ITA TATSUMI, TORU TAKANO, Yoshio MURAKAMI*, TOSHIHIRO TAKAO**, \\ NORIYOSHI YAMAKITA***, SHIGEYUKI TAHARA ${ }^{\#}$, AKIRA TERAMOTO ${ }^{\#}$, KOZO HASHIMOTO**, \\ YUZURU KATO* AND NOBUYUKI AMINO
}

Department of Laboratory Medicine, Osaka University Graduate School of Medicine, Suita-shi, Osaka 565-0871, Japan

*First Division, Department of Medicine, Shimane Medical University, Izumo-shi, Shimane 693-8501, Japan

**The Second Department of Internal Medicine, Kochi Medical School, Nankoku-shi, Kochi 783-8505, Japan

***Department of Internal Medicine, Matsunami General Hospital, Kasamatsu-cho, Gifu 501-6062, Japan

\#Department of Neurosurgery, Nippon Medical School, Bunkyo-ku, Tokyo 113-8603, Japan

\begin{abstract}
A previous study reported a high prevalence of autoantibodies to alpha-enolase in lymphocytic hypophysitis and these antibodies efficiently distinguished lymphocytic hypophysitis from pituitary tumors. To confirm this, we examined autoantibodies to alpha-enolase in patients with lymphocytic hypophysitis $(\mathrm{n}=17)$, pituitary non-functioning adenoma $(n=13)$, other pituitary diseases $(n=17)$ and other autoimmune diseases $(n=30)$, and compared to healthy controls $(n=46)$. Autoantibodies were found in $41.2 \%, 46.2 \%, 23.5 \%, 20.0 \%$ and $4.3 \%$, respectively. Our findings indicate that detection of anti-alpha-enolase antibodies is not suitable for specific diagnosis of lymphocytic hypophysitis.
\end{abstract}

Key words: Autoantibody, Enolase, Lymphocytic hypophysitis, Pituitary Adenoma

(Endocrine Journal 50: 697-702, 2003)

LYMPHOCYTIC hypophysitis is an autoimmune disease in the pituitary gland, but its pathogenesis remains unclear $[1,2]$. The pituitary gland may enlarge in the early stage of lymphocytic hypophysitis and in the late stage may be either atrophic or present as an empty sella $[1,2]$. Therefore, it is difficult to distinguish lymphocytic hypophysitis from other pituitary diseases, such as tumor or empty sella, by computed tomography. Magnetic resonance imaging improves the visualization of the pituitary gland but the diagnosis of lymphocytic hypophysitis still requires histological examination. Recently, we developed experimental lymphocytic hypophysitis and found that the major antigens are growth hormone, thyrotropin, and luteinizing hormone [3]. Crock showed autoantibodies reactive to a $49-\mathrm{kDa}$ pituitary

Received: April 25, 2003

Accepted: July 22, 2003

Correspondence to: Dr. Nobuyuki AMINO, Department of Laboratory Medicine, Osaka University Graduate School of Medicine D2, 2-2, Yamada-oka, Suita, Osaka 565-0871, Japan cytosolic protein in 70\% of biopsy-proven lymphocytic hypophysitis and $55 \%$ of suspected hypophysitis [4]. Recently, this group clarified that the $49-\mathrm{kDa}$ pituitary cytoplasmic protein was alpha-enolase $[5,6]$. However, autoantibodies to alpha-enolase were found to be common markers of autoimmune diseases [7, 8]; for example, autoantibodies were found in $27 \%$ of patients with systemic lupus erythematosus and 30\% of patients with systemic sclerosis [7]. Enolase has been characterized as a highly conserved cytoplasmic glycolytic enzyme that may be involved in differentiation $[9,10]$, and alpha-enolase expression has been detected in most cells [11, 12]. This protein plays a role in converting phosphoglyceric acid to phosphoenolpyruvic acid in the glycolytic pathway $[13,14]$.

This extremely high frequency of autoantibodies to alpha-enolase prompted us to undertake re-evaluation of the presence of autoantibodies in various pituitary diseases. We found similar high prevalence of antibodies even in patients with pituitary non-functioning adenoma. 


\section{Materials and Methods}

\section{Subjects}

Serum samples were obtained from 17 patients with lymphocytic hypophysitis (5 with lymphocytic adenohypophysitis and 12 with lymphocytic infundibuloneurohypophysitis, including 3 from the latter group with diagnosis proven by biopsy), 13 with pituitary non-functioning macroadenoma, 17 with other pituitary diseases (10 with isolated ACTH deficiency, 4 with idiopathic TSH deficiency, and 3 with Sheehan syndrome), 30 with other autoimmune diseases (10 with Graves' disease, 10 with Hashimoto's thyroiditis, and 10 with rheumatoid arthritis), and 46 healthy controls. Lymphocytic adenohypophysitis was suspected by pituitary dysfunction associated with an intrasellar mass which demonstrated gadolinium enhancement on MRI. The remaining lymphocytic infundibuloneurohypophysitis were diagnosed by the presence of central diabetes insipidus, with swelling of the posterior pituitary or pituitary stalk on MRI. Pituitary nonfunctioning macroadenoma was diagnosed by histological examination. We obtained informed consent from all patients. The mean ages and sex distribution are summarized in Table 1. The mean ages of the groups of patients were not significantly different from the mean age of the healthy controls.

\section{Detection of autoantibodies to alpha-enolase by radio- ligand assay}

The precise method of radioligand assay was described in our previous report $[15,16]$. The openreading frame of alpha-enolase was obtained by RTPCR amplification using poly-A RNA from the human hippocampus (Clontech Laboratories, Inc., Palo Alto,
CA) as a template. The first strand of cDNA was synthesized using ReverTraAce (Toyobo, Tokyo, Japan) with random hexamers according to the manufacturer's instructions. PCR using the following primer pairs, 5'-GGAATTCATGTCTATTCTCAAGA TCCATGC-3' and 5'-GGTGGAAAGTGAGGCGAG AAAAACAATGAC-3' (the $E c o R$ I site is underlined), was used. PCR was carried out using KOD-plus (Toyobo) as a DNA polymerase. cDNA was digested with an $E c o R$ I and a Xho I (human alpha-enolase had a Xho I site after the stop codon) and ligated into the pET28a (+) expression vector (Novagen, Madison, WI). $\left[{ }^{35} \mathrm{~S}\right]$-methionine labeled protein was produced using cDNA, TNT Quick coupled Transcription/ Translation System (Promega, Madison, WI), and $\left.{ }^{[35} \mathrm{S}\right]$-methionine (Amersham Biotech, Arlington Heights, IL) according to the manufacturer's instructions. Then, $\left.{ }^{35} \mathrm{~S}\right]$-methionine labeled protein was applied to a Nick column (Amersham Biotech) to remove free $\left[{ }^{35} \mathrm{~S}\right]$-methionine, and electrophoresed to SDSPAGE (10\% polyacrylamide gel). Autoradiography demonstrated the presence of a band consistent with alpha-enolase. The patients sera (dilution $1: 50$ ) and reaction mixtures containing 20,000 counts per minute (cpm) of labeled alpha-enolase were incubated overnight at $4{ }^{\circ} \mathrm{C}$, in a total volume of $50 \mu \mathrm{l}$, in reaction buffer $(50 \mathrm{mmol} /$ liter Tris- $\mathrm{HCl}, 150 \mathrm{mmol} /$ liter $\mathrm{NaCl}$, $0.1 \%$ BSA, $0.1 \%$ Tween-20, and $0.1 \% \mathrm{NaN}_{3}, \mathrm{pH} 7.4$ ). The reaction mixtures were transferred to each well in a 96-well filtration plate (Millipore Corp., Bedford, MA), which had been pretreated with blocking buffer ( $50 \mathrm{mmol} /$ liter Tris-HCl, $150 \mathrm{mmol} /$ liter $\mathrm{NaCl}, 3 \%$ BSA, and $0.1 \% \mathrm{NaN}_{3}, \mathrm{pH} 7.4$ ) at $4^{\circ} \mathrm{C}$ overnight. Ten $\mu$ l of $50 \%$ Protein G Sepharose 4FF (Amersham Bioscience) was added to each well to isolate the immune complex and then the plate was incubated for $45 \mathrm{~min}$ at room temperature. The plate was washed 10

Table 1. Age, sex, and autoantibodies to alpha-enolase in patients with lymphocytic hypophysitis, pituitary non-functioning adenoma, other pituitary diseases, other autoimmune diseases, and healthy controls.

\begin{tabular}{|c|c|c|c|c|c|}
\hline \multicolumn{6}{|c|}{ Autoantibodies to alpha-enolase } \\
\hline Subjects & $\begin{array}{l}\text { Number } \\
\text { examined }\end{array}$ & $\begin{array}{l}\text { Age (years) } \\
(\text { mean } \pm \mathrm{SD})\end{array}$ & Male/Female & $\begin{array}{l}\text { Number of positive } \\
\text { autoantibodies (\%) }\end{array}$ & $\begin{array}{c}\text { Index } \\
(\text { mean } \pm \mathrm{SD})\end{array}$ \\
\hline Lymphocytic hypophysitis & 17 & $43.8 \pm 17.9$ & $8 / 9$ & $7(41.2)$ & $1.23 \pm 0.43 *$ \\
\hline Pituitary non-functioning adenoma & 13 & $52.1 \pm 12.4$ & $2 / 11$ & $6(46.2)$ & $1.24 \pm 0.46$ \\
\hline Other pituitary diseases & 17 & $58.1 \pm 16.9$ & $8 / 9$ & $4(23.5)$ & $1.16 \pm 0.33 *$ \\
\hline Other autoimmune diseases & 30 & $46.8 \pm 14.7$ & $7 / 23$ & $6(20.0)$ & $1.08 \pm 0.39$ \\
\hline Healthy controls & 46 & $45.5 \pm 13.8$ & $21 / 25$ & $2(4.3)$ & $0.95 \pm 0.24$ \\
\hline
\end{tabular}

*The mean anti-enolase antibody index is significantly higher than that in healthy controls $(\mathrm{p}<0.05)$. 
times with $200 \mu \mathrm{l}$ washing buffer $(50 \mathrm{mmol} / \mathrm{liter}$ Tris$\mathrm{HCl}, 150 \mathrm{mmol} /$ liter $\mathrm{NaCl}$, and $1 \%$ Tween-20, $\mathrm{pH} 7.4$ ) using vacuum manifold (Millipore). The filter was dried and OptiPhase SuperMix (Perkin Elmer Life Sciences, Boston, MA) was added to each well before the quantity of precipitated labeled protein was counted in a 1450 MicroBeta TriLux apparatus (Perkin Elmer Life Sciences). All samples were measured in duplicate. The intra-assay coefficient of variation with these radioligand assays varied from 4.25 to $6.01 \%$, while the inter-assay coefficient of variation varied from 5.71 to $9.35 \%$. The results were expressed as an Anti-Enolase Index by the following formula: [cpm of the sample serum]/ [cpm of the normal pooled serum].

An antibody index greater than the cut-off value was considered to be positive. The cut-off value (1.43) was calculated as the mean $+2 \mathrm{SD}$ in healthy controls.

\section{Statistical methods}

Differences between the mean Anti-Enolase Index in subjects and in healthy controls were determined by Mann-Whitney $U$-test. Mann-Whitney $U$-test was carried out using the StatView 4.0 software program (Abacus Concepts, Berkeley, CA) for the Macintosh computer. A $P$ value less than 0.05 was considered statistically significant.

\section{Results}

The mean Anti-Enolase Index was significantly higher in patients with lymphocytic hypophysitis $(\mathrm{p}<$ 0.05 ) and in the group of subjects with other pituitary diseases $(p<0.05)$ than in healthy controls (Table 1$)$.

Seven patients $(41.2 \%)$ with lymphocytic hypophysitis, $6(46.2 \%)$ with pituitary non-functioning adenoma, $4(23.5 \%)$ with other pituitary diseases $(2$ with isolated ACTH deficiency and 2 with Sheehan syndrome), 6 (20.0\%) with other autoimmune diseases (1 with Graves' disease, 2 with Hashimoto' thyroiditis, and 3 with rheumatoid arthritis), and $2(4.3 \%)$ healthy controls were positive for antibodies to alpha-enolase (Fig. 1, Table 1). In lymphocytic hypophysitis, 1 (20.0\%) with lymphocytic adenohypophysitis and 6 $(50.0 \%)$ with lymphocytic infundibuloneurohypophysitis were positive for antibodies to alpha-enolase, respectively.

\section{Discussion}

Crock found that $70 \%$ of patients with biopsy proven lymphocytic hypophysitis had autoantibodies to a $49-\mathrm{kDa}$ cytosolic antigen and $20 \%$ of patients with hypopituitarism secondary to tumor had these antibodies, as detected by immunoblotting method [4]. Therefore, she reported that these antibodies might help to elucidate the pathogenesis of lymphocytic hypophysitis. Recently, O'Dwyer et al. identified this antigen was alpha-enolase [5, 6]. Therefore, we examined autoantibodies to alpha-enolase in patients with pituitary diseases by radioligand assay and found a similar prevalence of these antibodies in patients with lymphocytic hypophysitis. However, the sera from the patients with pituitary non-functioning adenoma showed a similarity to lymphocytic hypophysitis in terms of the frequency of autoantibodies. Autoantibodies to alpha-enolase were found not only in autoimmune pituitary diseases but also in other autoimmune diseases [7, 8]. Thus, anti-alpha-enolase antibodies are not organ-specific and the presence of these antibodies suggests the presence of an autoimmune-background.

The discrepancy between our results and Crock's group of patients with pituitary tumor may be explained by the different analytical methods. Radioligand assay detects natural conformational epitope of antigens, while the immunoblotting method may detect denatured antigen. It has already been shown that radioligand assay detects autoantibodies even against conformational antigens $[17,18]$. O'Dwyer $e t$ al. [6] purified enolase using goat polyclonal antienolase antibodies (C-19) (Santa Cruz Biotechnology, Inc., Santa Cruz, CA), but in our study these antibodies could not detect recombinant alpha-enolase by radioligand assay (data not shown). Instead of that antibody (C-19), in the present study we used rabbit polyclonal anti-enolase antibodies (H-300) (Santa Cruz Biotechnology), and found that they (H-300) were useful as a positive standard (data not shown). Therefore, the "purified protein" in the study by O'Dwyer et al. might not be alpha-enolase.

Our study showed high prevalence of autoantibodies to alpha-enolase in patients with lymphocytic infundibuloneurohypophysitis. Other patients with neurological disorders such as Hashimoto's encephalopathy [19] also had frequent presence of these antibodies. Thus these neurological diseases may have 


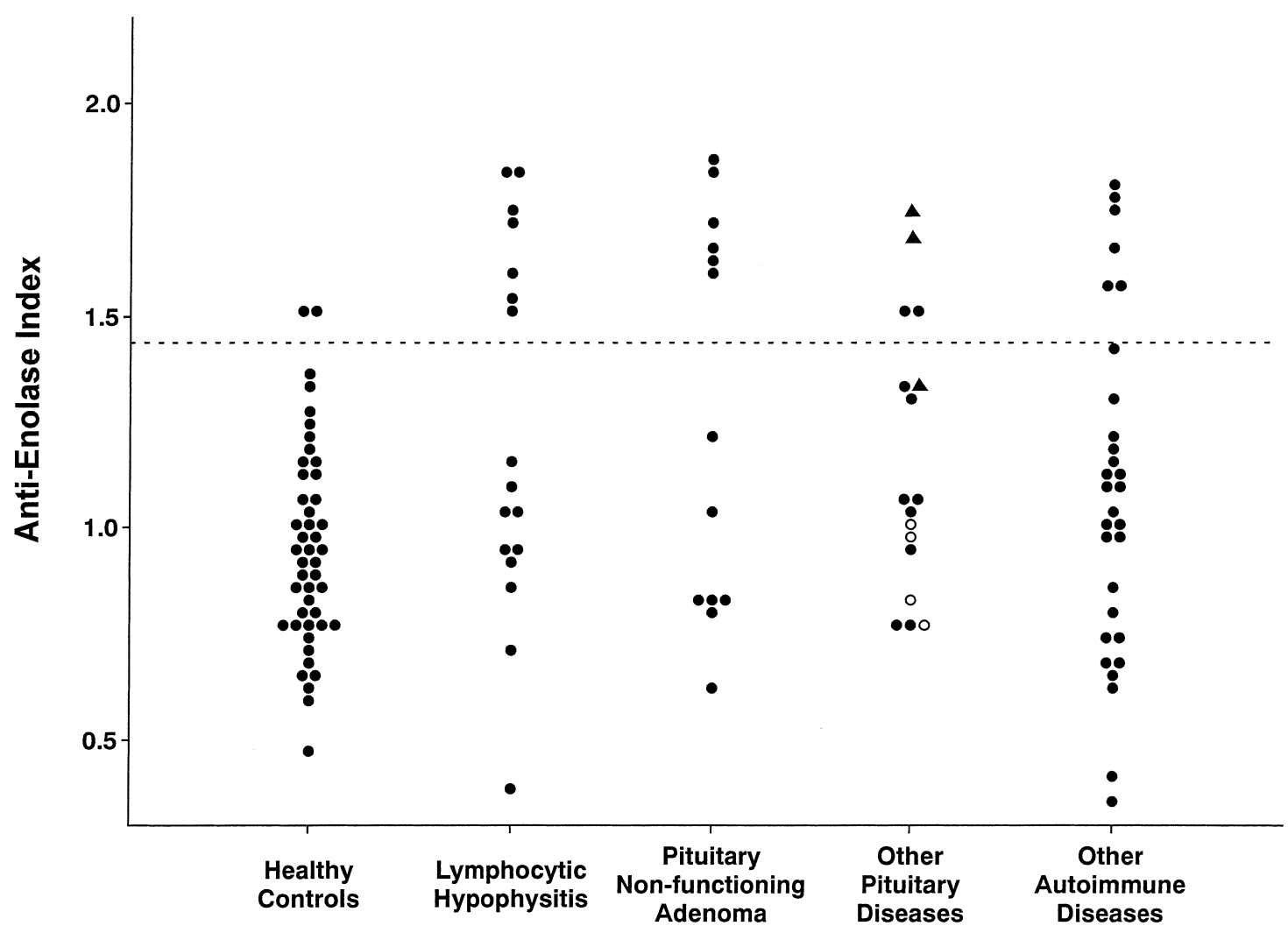

Fig. 1. Index of antibodies to human alpha-enolase in patients with lymphocytic hypophysitis, pituitary non-functioning adenoma, other pituitary diseases ( 1 isolated ACTH deficiency, $\boldsymbol{\Delta}$ Sheehan syndrome, $\bigcirc$ idiopathic TSH deficiency), other autoimmune diseases and healthy controls. Dotted line denotes mean +2 SD levels of healthy controls.

somewhat similar background of autoimmune abnormality.

The isolated ACTH deficiency in some patients may be induced by autoimmune mechanism in pituitary gland $[20,21]$. In this study, anti-alpha-enolase antibodies were found in $20 \%$ of the patients with isolated ACTH deficiency. It is interesting to note that the same prevalence $(20 \%)$ of antibodies was observed in patients with lymphocytic adenohypophysitis. Considering these points, some of patients with isolated ACTH deficiency might have intimate association with lymphocytic hypophysitis.

Autoantibodies to alpha-enolase were detected in $63.1 \%$ of patients with Sheehan syndrome [22]. In our study, 2 of 3 patients with Sheehan syndrome showed positive antibodies. Sheehan syndrome has long been thought to be induced by postpartum necrosis of pituitary gland $[23,24]$. Lymphocytic hypophysitis is also frequently observed after delivery and it is interesting to speculate that so called Sheehan syndrome may have some relation to lymphocytic hypophysitis. The necrosis of the large pituitary gland may be induced by immune reaction against the pituitary gland, because immunological abnormalities are also described in patients with primary empty sella syndrome [25], which is caused by destruction in the pituitary gland. In the later stages of lymphocytic hypophysitis, the pituitary gland may atrophied, leaving an empty sella $[1,2]$. Anti-alpha-enolase antibodies could be detected not only in patients with lymphocytic hypophysitis but also in other pituitary diseases. Therefore, antialpha-enolase antibodies are not suitable as a marker for the specific diagnosis of lymphocytic hypophysitis.

\section{Acknowledgements}

This study was performed as a part of special research projects by the Japan National Research Group on Hypothalamo-Pituitary Disorders. This work was also supported by Grants-in-Aid for Scientific Research to N.A. (no. 12877388 and no. 14207107) and 
K.T. from the Ministry of Education, Science and Culture of Japan, and from the Ministry of Health, Labour and Welfare of Japan, and the Foundation for Growth Science in Japan. We also thank Ms. Rika Kamada for skillful assistance.

\section{References}

1. Hashimoto K, Takao T, Makino S (1997) Lymphocytic adenohypophysitis and lymphocytic infundibuloneurohypophysitis. Endocr J 44: 1-10.

2. Beressi N, Beressi JP, Cohen R, Modigliani E (1999) Lymphocytic hypophysitis. A review of 145 cases. Ann Med Inter (Paris) 150: 327-341.

3. Watanabe K, Tada H, Shimaoka Y, Hidaka Y, Tatsumi K, Izumi Y, Amino N (2001) Characteristics of experimental autoimmune hypophysitis in rats: major antigens are growth hormone, thyrotropin, and luteinizing hormone in this model. Autoimmunity 33: 265-274.

4. Crock PA (1998) Cytosolic autoantigens in lymphocytic hypophysitis. J Clin Endocrinol Metab 83: 609618.

5. O'Dwyer DT, Clifton V, Hall A, Smith R, Robinson PJ, Crock PA (2002) Pituitary autoantibodies in lymphocytic hypophysitis target both gamma- and alpha-enolase-a link with pregnancy? Arch Physiol Biochem 110: 94-98.

6. O'Dwyer DT, Smith AI, Matthew ML, Andronicos NM, Ranson M, Robinson PJ, Crock PA (2002) Identification of the $49-\mathrm{kDa}$ autoantigen associated with lymphocytic hypophysitis as alpha-enolase. J Clin Endocrinol Metab 87: 752-757.

7. Gitlits VM, Toh BH, Sentry JW (2001) Disease association, origin, and clinical relevance of autoantibodies to the glycolytic enzyme enolase. J Investig Med 49: 138-145.

8. Pratesi F, Moscato S, Sabbatini A, Chimenti D, Bombardieri S, Migliorini P (2000) Autoantibodies specific for alpha-enolase in systemic autoimmune disorders. J Rheumatol 27: 109-115.

9. Verma M, Dutta SK (1994) DNA sequences encoding enolase are remarkably conserved from yeast to mammals. Life Sci 55: 893-899.

10. Whitehead MC, Marangos PJ, Connolly SM, Morest DK (1982) Synapse formation is related to the onset of neuron-specific enolase immunoreactivity in the avian auditory and vestibular systems. Dev Neurosci 5: 298307.

11. Deloulme JC, Helies A, Ledig M, Lucas M, Sensenbrenner M (1997) A comparative study of the distribution of alpha- and gamma-enolase subunits in cultured rat neural cells and fibroblasts. Int J Dev Neurosci 15: 183-194.

12. Sensenbrenner M, Lucas M, Deloulme JC (1997) Expression of two neuronal markers, growth-associated protein 43 and neuron-specific enolase, in rat glial cells. J Mol Med 75: 653-663.

13. Keller A, Berod A, Dussaillant M, Lamande N, Gros F, Lucas M (1994) Coexpression of alpha and gamma enolase genes in neurons of adult rat brain. $J$ Neurosci Res 38: 493-504.

14. Zhang E, Brewer JM, Minor W, Carreira LA, Lebioda L (1997) Mechanism of enolase: the crystal structure of asymmetric dimer enolase-2-phospho-D-glycerate/ enolase-phosphoenolpyruvate at 2.0 A resolution. Biochemistry 36: 12526-12534.

15. Tanaka S, Tatsumi K, Kimura M, Takano T, Murakami Y, Takao T, Hashimoto K, Kato Y, Amino N (2002) Detection of autoantibodies against the pituitaryspecific proteins in patients with lymphocytic hypophysitis. Eur J Endocrinol 147: 767-775.

16. Tanaka S, Tatsumi K, Tomita T, Kimura M, Takano T, Yoshikawa H, Amino N (2003) Novel autoantibodies to pituitary gland specific factor $1 \mathrm{a}$ in patients with rheumatoid arthritis. Rheumatology (Oxf) 42: 353-356.

17. Kimura M, Tatsumi KI, Tada H, Ikemoto M, Fukuda Y, Kaneko A, Kato M, Hidaka Y, Amino N (2000) Enzyme immunoassay for autoantibodies to human liver-type arginase and its clinical application. Clin Chem 46: 112-117.

18. Yamamoto AM, Amoura Z, Johannet C, Jeronimo AL, Campos H, Koutouzov S, Piette JC, Bach JF (2000) Quantitative radioligand assays using de novo-synthesized recombinant autoantigens in connective tissue diseases: new tools to approach the pathogenic significance of anti-RNP antibodies in rheumatic diseases. Arthritis Rheum 43: 689-698.

19. Ochi H, Horiuchi I, Araki N, Toda T, Araki T, Sato K, Murai H, Osoegawa M, Yamada T, Okamura K, Ogino T, Mizumoto K, Yamashita H, Saya H, Kira J (2002) Proteomic analysis of human brain identifies alphaenolase as a novel autoantigen in Hashimoto's encephalopathy. FEBS Lett 528: 197-202.

20. Notsu K, Oka N, Sohmiya M, Sato T, Ando S, Moritake K, Inada K, Osamura Y, Kato Y (1994) Isolated adrenocorticotrophin deficiency associated with anti-pituitary antibodies, pituitary cyst, sphenoidal cyst and pineal tumor. Endocr J 41: 631-637.

21. Escobar-Morreale H, Serrano-Gotarredona J, Varela C (1994) Isolated adrenocorticotropic hormone deficiency due to probable lymphocytic hypophysitis in a man. J Endocrinol Invest 17: 127-131. 
22. Goswami R, Kochupillai N, Crock PA, Jaleel A, Gupta N (2002) Pituitary autoimmunity in patients with Sheehan's syndrome. J Clin Endocrinol Metab 87: 4137-4141.

23. Sheehan HL (1937) Postpartum necrosis of the pituitary. J Pathol Bacteriol 45: 189.
24. Sheehan HL, Davies JC (1968) Pituitary necrosis. $B r$ Med Bull 24: 59-70.

25. Mau M, Phillips TM, Ratner RE (1993) Presence of anti-pituitary hormone antibodies in patients with empty sella syndrome and pituitary tumours. Clin Endocrinol (Oxf) 38: 495-500. 